GANDRUNG: Jurnal Pengabdian Kepada Masyarakat ISSN: 2721-6136 (Online)

\title{
Mentoring for the VI East Java Teaching Team Sports Basketball Banyuwangi Regency
}

\author{
Ach. Zayul M¹, Galih Farhanto², Donny Setiawan³ \\ 1, 2, 3PGRI Banyuwangi University \\ Email: 1azuzuli74@gmail.com, 2galihfarhanto19@gmail.com,3donnysetiawaneva@gmail.com,

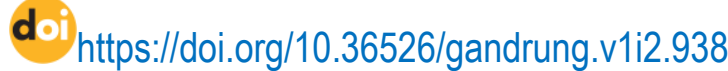

\begin{abstract}
Porprov VI East Java Province will be held in four districts namely Gresik, Bojonegoro, Tuban and Lamongan. Banyuwangi Regency participates in this multi-event sports event held every 2 years with great enthusiasm. Where preparation as well as pre Porprov has been followed. One of the sports that is attracting enough attention is the women's Basketball sports. Where in the pre-warm-up event Porprov was able to wipe out all matches with a win. Plus in this generation there are 2 heroines from Gandrung who represent East Java to take part in Pre-PON, adding to the solid Banyuwangi women's basketball team. Naturally, the management of the coach is targeting this team to enter the final round in this VI VI porprov. In this Porprov we provide assistance to the women's basketball coach team to help maintain the physical and psychological condition of the athletes in attending this event. With a fairly tight schedule to compete 1 time a day makes the athlete's physical and psychological decline. So we provide the right method to recover physically and psychologically from athletes who face a hectic schedule. The method for carrying out this activity is (a) the preparation phase (b) the implementation phase of the mentoring at each match (c) the evaluation phase, which is to make a final report. The results of this mentoring activity were very positive, this can be seen (1) the Banyuwangi basketball women's team entered the final round and won the silver medal (2) the physical and psychological condition of the athlete was always maintained every day proved that there were no athletes who were injured and under perform, (3) the assistance process went smoothly without any significant obstacles.
\end{abstract}

Keyword: Assistance, basketball, athlete, physical and psychological.

\section{Pendahuluan}

Diharapkan dalam Porprov VI ini bola basket putri Banyuwangi masuk ke babak final dan mampu meraih emas. Tentu hal tersebut bukanlah hal yang mudah, dimana faktor teknis dan non teknis harus dipersiapkan oleh tim. Persiapan memang sudah dimulai sejak jauh-jauh hari oleh tim bola basket putri, dimana mengadakan try out ke Bali dan Surabaya untuk melawan tim dari daerah-daerah tersebut. Memang factor fisik dan psikis yang tidak konsisten masih membayangi tim ini. Kondisi fisik yang prima sangat dibutuhkan dalam permainan bola basket, sistem dan pola permainan yang selalu bergerak aktif tentu memerlukan persyaratan fisik yang baik untuk dapat bermain secara maskimal (Febrianti, N.2019). Selain factor fisik factor psikologis dari atlet juga akan mempengaruhi dari pertandingan yang dijalani oleh seorang atlet. Dampak-dampak berupa perubahan emosi, penurunan percaya diri, kehilangan identitas merupakan factor yang dapat mempengaruhi psikologis dari atlet (Amelia \& Kurniawan. 2014) 
GANDRUNG: Jurnal Pengabdian Kepada Masyarakat ISSN: 2721-6136 (Online)

2 faktor tesebut tentunya harus tetap dijaga oleh setiap pemain untuk menjaga performa yang maksimal, tentunya dibantu oleh tim official yang mendampingi mereka.

Faktor fisik dan psikologis tersebut dibutuhkan bagi setiap pemain, tidak terkecuali pada pemain bola basket. Apalagi dalam Porprov ini pertandingan dilakukan setiap hari tanpa jeda seharipun, sehingga membutuhkan fisik dan psikologis yang yang baik untuk menjalani pertandingan demi pertandingan dalam Porprov. Tentunya jika pemain basket putri ini ingin membawa prestasi yang baik dalam ajang Porprov kali ini harus memilki factor fisik dan psikologis yang baik dan optimal. Keberhasilan dari seorang atlet dipengaruhi oleh sejumlah factor yang saling mendukung antara factor satu dengan factor lainnya meliputi factor fisik dan psikis yang optimal (Bandi Utama,AM. 2011).

\section{Metode}

Berdasarkan permasalahan yang sudah dijelaskan di atas maka ada beberapa metode yang dilaksanakan pada saat pengabdian yaitu :

1. Bekerja sama dengan tim manajemen Porprov cabang bola basket putri Banyuwangi untuk pendampingan atlet.

2. Mengajak serta tim yang berkompeten dalam aspek psikologis untuk meberikan pendampingan psikologis atlet saat Porprov berlangsung

3. Memberikan program latihan fisik dan psikologis kepada seluruh atlet saat Porprov berlangsung.

Pelaksanaan pengabdian dilakukan mulai tanggal 05-13 Juni 2019. Adapun susunan kegiatan adalah sebagai berikut:

Tabel 1. Agenda Kegiatan

\begin{tabular}{clc}
\hline No & \multicolumn{1}{c}{ Kegiatan } & Tanggal Pelaksanaan \\
\hline 1 & $\begin{array}{l}\text { Pendampingan Babak Penyisihan Grup vs } \\
\text { Jember }\end{array}$ & 06 Mei 2019 \\
\hline 2 & $\begin{array}{l}\text { Pendampingan Babak Penyisihan Grup vs } \\
\text { Pasuruan }\end{array}$ & 07 Mei 2019 \\
\hline 3 & $\begin{array}{l}\text { Pendampingan Babak Penyisihan Grup vs } \\
\text { Kediri }\end{array}$ & 08 Mei 2019 \\
\hline 4 & Pendampingan Babak 8 Besar vs Malang & 10 Mei 2019 \\
\hline 5 & $\begin{array}{l}\text { Pendampingan Babak Semifinal Besar vs } \\
\text { Madiun }\end{array}$ & 11 Mei 2019 \\
\hline 6 & Pendampingan Babak Final vs Surabaya & 12 Mei 2019 \\
\hline
\end{tabular}




\section{Hasil dan Diskusi}

Kebutuhan fisik atlet dalam sebuah pertandingan yang levelnya tinggi memerlukan pendampingan serta pemberian program dan jadwal kegiatan yang tepat agar keadaan fisik dari atlet siap untuk bertanding. Jadwal bertanding yang cukup padat dijalani atlet cabang bola basket putri Banyuwangi di Porprov ke-6. Kesiapan fisik dan mental menjadi ujian yang mampu dilewati oleh para pemain dengan mengikuti jadwal yang sudah ditentukan dan mendapat pendapingan psikologis yang cukup baik selama mengikuti Porprov. Pertandingan yang dijalani selama 7 hari pun dilalui dengan hasil yang memuaskan, dengan membawa medali perak adalah bukti kerja keras dan penanganan atlet yang cukup baik. Dimana untuk bisa mencapai prestasi maksimal dibutuhkan kemampuan fisik, teknik, taktik,dan mental ( Fadli \& Anshor, 2019).

Di hari pertama tentunya atlet mempunyai fisik yang cukup prima karena mempunyai kesiapan fisik yang bagus, namun ada sedikit kendala di factor mental bertanding dimana sebagian besar atlet merupakan wajah baru yang baru pertama kali tampil di ajang ini. Butuh adaptasi yang banyak bagi mereka untuk bisa bermain sesuai performa maksimal mereka. Meskipun di pertandingan pertama mereka mampu meraih kemengangan tapi mental bertanding mereka masih belum terbentuk, terutama pemain junior. Sehingga setelah pertandingan diadakan evaluasi dan pendampingan dengan memberikan motivasi untuk lebih baik bertanding di hari berikutnya. Pada pertandingan pertama tentunya masalah fisik masih belum kedodoran karna pemain masih dalam kondisi prima karena baru melakoni satu pertandingan.

Pada hari kedua pertandingan yang cukup menentukan dimana jika mampu memenangkan pertandingan maka bisa dipastikan tim mampu melaju ke babak 8 besar, meskipun masih ada pertandingan ketiga yang akan dilalui. Sehingga beban bermain tim semakin berat, sehingga kami memberikan motivasi yang lebih untuk tetap fokus kepada pertandingan, sebelum pertandingan bisa mencairkan suasana untuk membuat pemain mengurangi ketegangannya. Tentunya dengan kondisi pemain yang sehari sebelumnya juga bertanding maka untuk latihan fisik cukup latihan dengan intensitas ringan saja. Pada akhirnya di pertandingan kedua pun tim membawa kemenangan tetapi dengan masalah yang sama mental bertanding lagi-lagi masih belum maksimal bagi pemain junior, sehingga tim kembali memberikan pendampingan psikologi dengan memberikan suntikan semangat dan moral, tim pelatih pun tetap memberikan evaluasi tetapi tidak diperkenankan memberi penilaian buruk kepada para pemain mereka untuk tidak membuat mental mereka lemah.

Pada hari ketiga kondisi fisik pemain mulai menurun tapi masih dalam kondisi normal, namun lawan yang dihadapi cukup kuat sehingga pada pertandingan ketiga ini tim mengalami kekalahan namun 
GANDRUNG: Jurnal Pengabdian Kepada Masyarakat ISSN: 2721-6136 (Online)

dalam posisi tetap lolos ke babak 8 besar dengan status juara grup. Menuju babak 8 besar tim mendapat libur 1 hari, sehingga bisa mendapatkan waktu untuk memulihkan kondisi fisik dan mental setelah 3 hari berturut-turut bermain di tiga pertandingan, tentu di dalam keadaan dimana di hari ketiga mengalami kekalahan, maka pemulihan psikologis atlet agak berat, kami pun memiliki inisiatif untuk memanfaatkan libur 1 hari tersebut untuk mengajak pemain untuk jalan-jalan ke obyek wisata agar mereka lebih santai lagi dan tidak larut dalam kekalahan terakhir yang akan berdampak pada pertandingan selanjutnya. Pemain yang tidak dapat mengatasi hal faktor psikoligis tentunya dapat menggagu performa dalam pertandingan ( Anira dkk.2017).

Pada pertandingan babak 8 besar tim bermain cukup bagus dan mental bermain dari tim sudah mulai nampak konsisten pengaruh dari refresing di hari sebelumnya dan fisik yang terjaga karena memiliki jeda 1 hari untuk tidak bertanding. Tim pun mendapat kemenangan sehingga berhak masuk ke babak semifinal. Dengan hasil yang demikian membuat psikologis mereka kembali naik dan lebih bersemangat, namun tentunya kami tetap terus mendapingi dan meberi evaluasi agar mereka tidak terlena dalam kemenangan dan tetap focus kepada pertandingan selanjutnya.

Babak semifinal performa dari para pemain masih terjaga dan juga mampu meraih kemenangan untuk melaju ke babak final memperebutkan medali emas. Tentunya di babak semifinal tim bekerja ekstra keras karena lawan yang ditemui cukup seimbang, fisik yang dikeluarkan lebih banyak ditambah lagi kelelahan yang mendera karena sudah melakoni 5 pertandingan dalam kurun waktu 6 hari, namun dengan mental yang sudah mulai stabil karena pemain pelapis pun sudah mulai berdaptasi sehingga bisa diandalkan untuk menjadi pelapis bagi pemain utama. Pemerataan teknik pemain yang relative sama memiliki nilai plus bagi tim ini dan tingkat psikologi yang semakin tinggi meskipun ada tekanan yang lebih tinggi juga di babak semifinal.

Di babak final tim putri berhadapan dengan juara bertahan Porprov sebelumnya, yaitu tim putri Kota Surabaya. Dari factor teknik sebenarnya tim Banyuwangi tidak berbeda jauh dengan Tim Kota Surabaya, sehingga kita masih memiliki peluang besar untuk meraih medali emas untuk tim putri kita. Di pertandingan final motivasi dan semangat tim bertambah besar karena merupakan pertandingan yang terakhir. Namun keberuntungan belum berpihak kepada tim kita, pada kuarter 1-3 sebenarnya tim kita mampu unggul dari tim lawan, namun karena pemain kita terlalu terlena dan menganggap kita bisa mengatasi tim lawan membuat tim kita lengah dikuarter yang keempat, sehingga tim kita harus rela meberikan medali emas kepada juara bertahan Kota Surabaya. Namun disisi lain mental, motivasi dan kepercayaan diri pemain sangat bagus dalam pertandingan final, fisik pun tetap optimal sampe kuarter akhir meskipun mengalami kelengahan di kuarter akhir. 
Secara umum penampilan dari tim Banyuwangi dari babak awal sampai babak final cukup memuaskan, dimana baru pertama kalinya tim basket putri masuk ke babak final dan meraih medali perak selama mengikuti Porprov sebelum-sebelumnya. Merupakan prestasi yang sangat bagus yang didapat oleh tim Banyuwangi. Semua pemain di akhir Porprov dalam kondisi yang baik, tidak ada yang cidera, psikologi mereka pun dalam kondisi yang baik dengan tidak berlarut-larut dalam kekalahan di final, bahkan merasa bangga bisa menyumbang medali perak bagi Kontingen Banyuwangi, bukan prestasi yang mudah yang ditorehkan oleh tim. Berdasar hasil tersebut dapat dikatakan proses pendampingan untuk menjaga kondisi fisik dan psikologi atlet bola basket putri pada Porprov ke-6 ini sangat membantu bagi kondisi tim menghadapi event ini. Faktor fisik, psikis, lingkungan, dan faktor lainya dapat mempengaruhi seseorang dalam proses pencapaian prestasi (Hardiyanto,B.2019).

\section{Kesimpulan}

Kegiatan pendampingan tersebut sangat penting dilakukan sebagai kegiatan yang sangat membantu dan berpengaruh positif terhadap pencapaian tim. Kegiatan pendampingan ini sebaiknya selalu dilakukan oleh tim agar dalam pertandingan kondisi fisik dan psikologi dari atlet tetap terjaga sehingga menghasilkan tujuan yang maksimal. Kegiatan ini dapat dimaksimalkan lagi dengan tim yang lebih professional lagi baik dari tim psikologi maupun tim fisiologi untuk kebutuhan fisik. Yang terpenting dari kegiatan ini mampu membantu tujuan dari tim putri bola basket meraih hasil yang maksimal yaitu medali perak untuk pertama kalinya.

Saran untuk kegiatan pengabdian masyarakat selanjutnya jika melakukan kegiatan yang serupa, yaitu :

1. Menambah Tim psikologisnya dari tim yang lebih professional lagi sehingga hasilnya akan lebih maksimal lagi

2. Menambah tim fisiologi untuk menambah pengetahuan dari segi kondisi fisik yang dimiliki oleh setiap atlet.

3. Sebaiknya pendampingan psikologi dan kondisi fisik selalu diikutsertakan ke dalam latihan maupun dalam pertandingan, agar atlet terbiasa dalam hal tersebut.

4. Tim manajemen pelatih sebaiknya ada yang bertugas sebagai tim analisis hasil pertandingan untuk mengetahui secara detail penurunan atau peningkatan dari masing-masing atlet. 
GANDRUNG: Jurnal Pengabdian Kepada Masyarakat ISSN: 2721-6136 (Online)

\section{Daftar Referensi}

Amelia \& Kurniawan. Penerimaan Diri pada Atlet Bola Basket yang Telah Mengalami Career-Ending Injury. Jurnal Psikologi Industri dan Organisasi. Vol03. No.02. 2014

Anira.2017. Tingkat Kecemasan Atlet Sebelum, Pada Saat Istirahat Dan Sesudah Pertandingan. Jurnal Terapan IImu Keolahragaan Vol.02 No.02 2017 Halaman 62-67. https://ejournal.upi.edu/index.php/JTIKOR/article/view/4948/6544

Bandi Utama,AM.2011. Aspek Psikologi dalam Atlet Tenis Meja. Fakultas IImu Keolahragaan, Universitas Negeri Yogyakarta.

Fadli \& Anshor. 2019. Survey Tentang Aspek-Aspek Psikologis Atlet Sepak Takraw Putra Sumut Dalam Menghadapi Pekan Olahraga Swilayah Viii Tahun 2011 Kepulauan Riau. Jurnal IImu Keolahragaan Vol. 18 (1), Januari - Juni 2019: 31 - 39. https://jurnal.unimed.ac.id/2012/index.php/JIK/article/view/14305/11804

Febrianti, N.2019. Analisis Komponen Fisik Terhadap Kemampuan Teknik Dasar Permainan Bola Basket Siswa SMA Katolik Cendrawasih Makasar.Fakultas IImu Keolahragaan, Universitas negeri Makasar.

Hardiyono,B. 2019. Tingkat Kecemasan Sebelum Bertanding Dan Percaya Diri Pada Saat Bertanding Atlet Pelatda Pengprov Fpti Sumatera Selatan. Jurnal IImiah Pendidikan Jasmani, 4 (1) 2020. https://ejournal.unib.ac.id/index.php/kinestetik/article/view/10399/5238 